Article

\title{
Synthesis and Crystal Structures of Azolo[b]1,3,4-Thiadiazinium Bromides
}

\section{Gerhard Laus *, Klaus Wurst and Herwig Schottenberger}

Faculty of Chemistry and Pharmacy, University of Innsbruck, 6020 Innsbruck, Austria; E-Mails: klaus.wurst@uibk.ac.at (K.W.); herwig.schottenberger@uibk.ac.at (H.S.)

* Author to whom correspondence should be addressed; E-Mail: gerhard.laus@uibk.ac.at; Tel.: +43-512-507-57080; Fax: +43-512-507-57099.

External Editor: Nikolaus Korber

Received: 29 October 2014; in revised form: 14 November 2014 / Accepted: 21 November 2014 / Published: 11 December 2014

\begin{abstract}
Three azolo[b]1,3,4-thiadiazinium bromides were prepared from the respective $N$-amino- $N$ '-methylazolethiones and phenacyl bromide, and their crystal structures were determined. 6-Phenyl-1-methylimidazo[2,1-b]1,3,4-thiadiazinium bromide (1) crystallized as methanol solvate ( $P 21 / n)$, 6-phenyl-1-methyl-1,2,4-triazolo[3,4-b]1,3,4-thiadiazinium bromide (2) as hemi-ethanol solvate $(P 21 / n)$, and 6-phenyl-1-methyl-1,2,4-triazolo[3,2-b]1,3,4-thiadiazinium bromide (3) solvent-free $(P 21 / c)$. Interionic contacts were identified.
\end{abstract}

Keywords: imidazole; thiadiazine; triazole

\section{Introduction}

$N$-Amino- $N$ '-alkylazolethiones are readily converted to the bicyclic annelated title compounds by condensation with $\alpha$-bromoketones. Several examples (alkyl $=$ substituted benzyl) of this reaction involving 4-amino- and 1-amino-1,2,4-triazolinethiones have been reported [1,2]. The synthesis of an analogous benzimidazole derivative starting from 1-amino-3-methylbenzimidazoline-2-thione has been described [3]. Since the portfolio of heterocyclic aminothiones has only recently been extended [4,5], we decided to compare the crystal structures of the closely related azolo[b]1,3,4-thiadiazinium bromides derived from the simplest representatives (alkyl $=$ methyl) of 1 -aminoimidazolinethione, 4-amino-1,2,4-triazolinethione and 1-amino-1,2,4-triazolinethione. Few reactions of the title compounds 
are known, such as the ring contraction to pyrazolo[5,1-c]1,2,4-triazoles or pyrazolo[1,5-a]benzimidazoles which are aromatic systems of the 3a-azapentalene type [6,7]. Thus far, no crystal structures of azolo[b]1,3,4-thiadiazinium salts have been reported.

\section{Results and Discussion}

The title compounds 1-3 were prepared from 1-amino-3-methylimidazoline-2-thione [4], from 4-amino-1-methyl-1,2,4-triazoline-5-thione [8,9], and from 1-amino-4-methyl-1,2,4-triazoline-5-thione [5], respectively, with phenacyl bromide in $\mathrm{EtOH}$ solution (Figure 1). The crystallographic data and refinement details are summarized in Table 1.

Table 1. Crystal data and refinement details.

\begin{tabular}{|c|c|c|c|}
\hline Compound & 1 & 2 & 3 \\
\hline CCDC No. & 1014167 & 1014168 & 1014169 \\
\hline Chemical formula & $\mathrm{C}_{12} \mathrm{H}_{12} \mathrm{~N}_{3} \mathrm{~S} \cdot \mathrm{Br} \cdot \mathrm{CH}_{4} \mathrm{O}$ & $\mathrm{C}_{12} \mathrm{H}_{14} \mathrm{~N}_{4} \mathrm{~S} \cdot \mathrm{Br} \cdot \mathrm{CH}_{3} \mathrm{O}_{0.5}$ & $\mathrm{C}_{11} \mathrm{H}_{11} \mathrm{~N}_{4} \mathrm{~S} \cdot \mathrm{Br}$ \\
\hline$M_{\mathrm{r}}$ & 342.26 & 334.24 & 311.21 \\
\hline Crystal size $/ \mathrm{mm}^{3}$ & $0.12 \times 0.10 \times 0.08$ & $0.18 \times 0.05 \times 0.04$ & $0.14 \times 0.11 \times 0.08$ \\
\hline Crystal system & Monoclinic & Monoclinic & Monoclinic \\
\hline Space group & $P 2_{1} / n$ & $P 2_{1} / n$ & $P 2_{1} / c$ \\
\hline$a / \AA$ & $10.0119(2)$ & $10.0118(2)$ & $6.8466(3)$ \\
\hline$b / \AA$ & $7.4539(1)$ & $7.0742(1)$ & $6.8350(3)$ \\
\hline$c / \AA$ & $20.1285(4)$ & $19.6760(4)$ & $27.0085(9)$ \\
\hline$\beta /{ }^{\circ}$ & $102.829(1)$ & $99.284(1)$ & $95.417(2)$ \\
\hline$V / \AA^{3}$ & $1464.65(5)$ & $1375.31(4)$ & $1258.26(9)$ \\
\hline$Z$ & 4 & 4 & 4 \\
\hline$D_{\mathrm{x}} / \mathrm{g} \mathrm{cm}^{-3}$ & 1.55 & 1.61 & 1.64 \\
\hline$\mu / \mathrm{mm}^{-1}$ & 2.95 & 3.13 & 3.42 \\
\hline$F(000) / \mathrm{e}$ & 696 & 676 & 624 \\
\hline$\theta_{\max } /{ }^{\circ}$ & 25.0 & 25.0 & 25.0 \\
\hline \multirow{3}{*}{$h, k, l$ range } & $-11 \leq h \leq 11$ & $-11 \leq h \leq 11$ & $-8 \leq h \leq 7$ \\
\hline & $-8 \leq k \leq 8$ & $-8 \leq k \leq 8$ & $-7 \leq k \leq 8$ \\
\hline & $-23 \leq l \leq 23$ & $-23 \leq l \leq 23$ & $-30 \leq l \leq 32$ \\
\hline Measured reflections & 8091 & 8591 & 6273 \\
\hline Independent reflections $\left(R_{\text {int }}\right)$ & $2565(0.036)$ & $2422(0.036)$ & $2182(0.039)$ \\
\hline Observed reflections $[I \geq 2 \sigma(I)]$ & 2235 & 2030 & 1821 \\
\hline Restraints, parameters & 0,187 & 6,180 & 0,155 \\
\hline$R_{1}, \mathrm{w} R_{2}[I \geq 2 \sigma(I)]$ & $0.029,0.079$ & $0.030,0.069$ & $0.043,0.080$ \\
\hline$R_{1}, \mathrm{w} R_{2}$ (all data) & $0.034,0.082$ & $0.040,0.072$ & $0.056,0.083$ \\
\hline Goodness of fit & 1.04 & 1.04 & 1.14 \\
\hline$\Delta \rho_{\max }, \Delta \rho_{\min } / \mathrm{e} \AA^{-3}$ & $0.28,-0.25$ & $0.42,-0.31$ & $0.46,-0.30$ \\
\hline
\end{tabular}

6-Phenyl-1-methylimidazo[2,1-b]1,3,4-thiadiazinium bromide crystallized from methanol and was obtained as methanol solvate $\mathbf{1}$. The imidazole rings are arranged parallel to $(25 \overline{2})$ and $(\overline{2} 52)$ planes. There are numerous $\mathrm{C}-\mathrm{H} \cdots \mathrm{Br}$ and $\mathrm{O}-\mathrm{H} \cdots \mathrm{Br}$ contacts forming a network (Figure 2 ). The oxygen position of the methanol molecule is disordered in the ratio 65:35. For hydrogen calculation, the carbon atoms of 
the solvent molecule were split into two positions with same coordinates and displacement parameters. The hydrogen bond parameters are summarized in Table 2.

Figure 1. Synthesis of 1,3,4-thiadiazinium bromides 1-3.

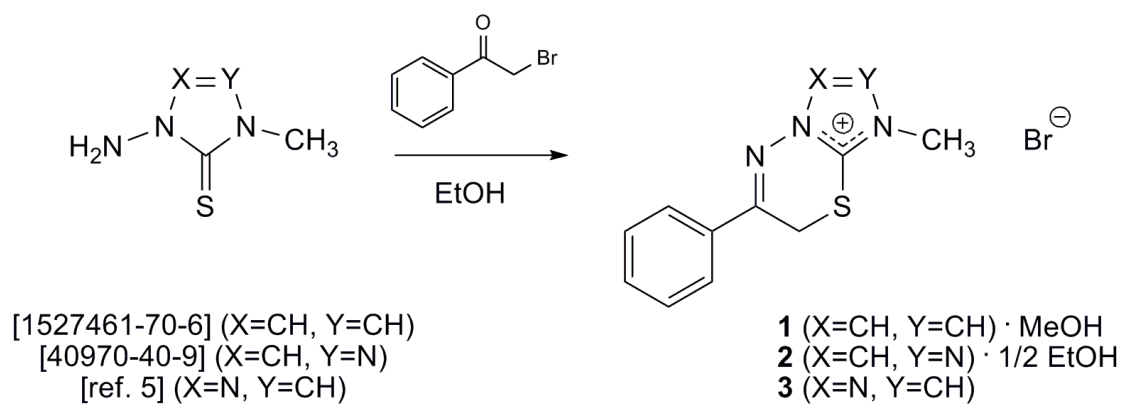

Figure 2. (a) ORTEP plot and atom numbering scheme of the cation; the displacement ellipsoids are drawn at the 50\% probability level; (b) Packing and hydrogen bonding of $\mathbf{1}$.

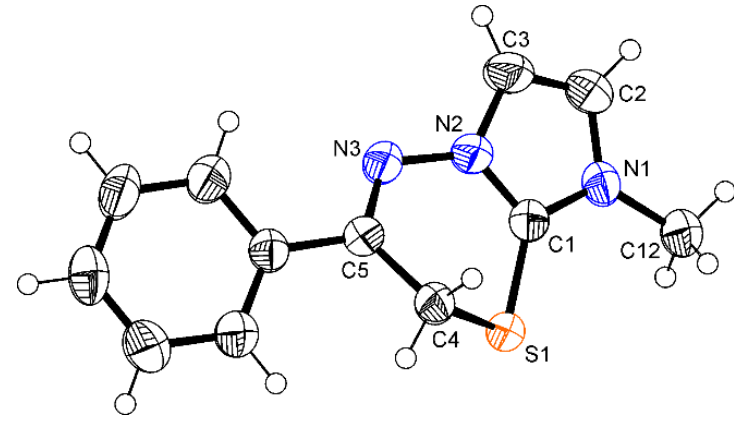

(a)

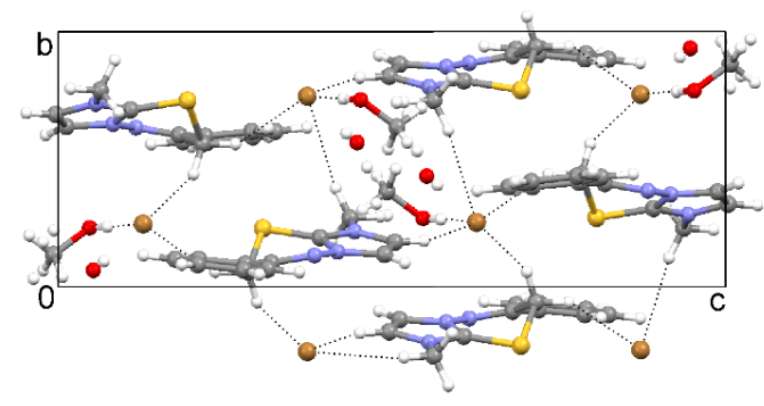

(b)

Table 2. Hydrogen bond parameters and short contacts $\left(\AA,^{\circ}\right)$.

\begin{tabular}{cccccc}
\hline Compound & Interaction & $\mathbf{H} \cdots \mathbf{A}$ & $\mathbf{D} \cdots \mathbf{A}$ & $\mathbf{D}-\mathbf{H} \cdots \mathbf{A}$ & Symmetry A \\
\hline \multirow{5}{*}{$\mathbf{1}$} & $\mathrm{O} 1-\mathrm{H}^{\cdots} \cdots \mathrm{Br}$ & 2.52 & $3.331(4)$ & 167 & $x, y, z$ \\
& $\mathrm{C} 4-\mathrm{H}_{\mathrm{A}} \cdots \mathrm{Br}$ & 2.86 & $3.590(2)$ & 132 & $1 / 2-x, 1 / 2+y, 1 / 2-z$ \\
& $\mathrm{C} 12-\mathrm{H}_{\mathrm{B}} \cdots \mathrm{Br}$ & 2.87 & $3.796(3)$ & 161 & $1-x,-y, 1-z$ \\
& $\mathrm{C} 4-\mathrm{H}_{\mathrm{B}} \cdots \mathrm{Br}$ & 2.90 & $3.749(2)$ & 146 & $x, y, z$ \\
& $\mathrm{C} 2-\mathrm{H}^{\cdots} \cdots \mathrm{Br}$ & 2.93 & $3.738(2)$ & 145 & $1-x,-y, 1-z$ \\
& $\mathrm{C} 12-\mathrm{H}_{\mathrm{C}} \cdots \mathrm{Br}$ & 2.96 & $3.871(2)$ & 157 & $x, 1+y, z$ \\
\hline \multirow{4}{*}{$\mathbf{2}$} & $\mathrm{O} 1 \cdots \mathrm{Br}$ & - & $2.49(1)$ & - & $x, y, z$ \\
& $\mathrm{C} 2-\mathrm{H}^{\cdots} \cdots \mathrm{Br}$ & 2.66 & $3.555(3)$ & 160 & $1-x,-y,-z$ \\
& $\mathrm{C} 3-\mathrm{H}_{\mathrm{A}} \cdots \mathrm{Br}$ & 2.78 & $3.518(3)$ & 132 & $3 / 2-x,-1 / 2+y, 1 / 2-z$ \\
& $\mathrm{C} 3-\mathrm{H}_{\mathrm{B}} \cdots \mathrm{Br}$ & 2.87 & $3.704(3)$ & 144 & $x, y, z$ \\
& $\mathrm{C} 11-\mathrm{H}_{\mathrm{C}} \cdots \mathrm{Br}$ & 2.95 & $3.767(4)$ & 142 & $x,-1+y, z$ \\
\hline \multirow{3}{*}{$\mathbf{3}$} & $\mathrm{C} 2-\mathrm{H}^{\cdots} \cdots \mathrm{Br}$ & 2.70 & $3.548(4)$ & 151 & $-x, 1-y, 1-z$ \\
& $\mathrm{C} 3-\mathrm{H}_{\mathrm{B}} \cdots \mathrm{Br}$ & 2.81 & $3.628(4)$ & 141 & $x,-1+y, z$ \\
& $\mathrm{C} 11-\mathrm{H}_{\mathrm{C}} \cdots \mathrm{Br}$ & 2.93 & $3.802(4)$ & 150 & $-x, 1-y, 1-z$ \\
\hline
\end{tabular}

6-Phenyl-1-methyl-1,2,4-triazolo[3,4-b]1,3,4-thiadiazinium bromide was recrystallized from methanol, but retained the reaction solvent and thus was obtained as hemi-ethanol solvate 2 . The triazole

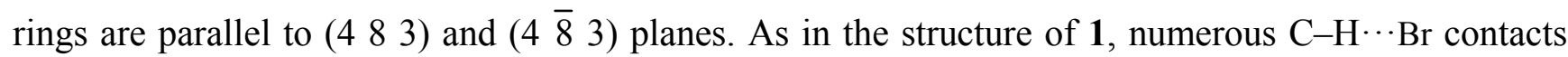


form a three-dimensional network (Figure 3). The ethanol molecule is located close to an inversion center (occupancy of 0.5 for each atom) and is additionally disordered in the ratio 1:1 for the positions of the hydroxyl and methyl group. These disordered positions were refined with isotropic displacement parameters, and bond restraints were used for the pertinent $\mathrm{C}-\mathrm{C}$ and $\mathrm{C}-\mathrm{O}$ bonds. Hydrogen atoms of the solvent molecule were omitted. An exceptionally short $\mathrm{O} 1 \cdots \mathrm{Br} 1$ distance is observed in the structure of compound 2. There are precedents of similar or even shorter $\mathrm{O} \cdots \mathrm{Br}$ contacts in the literature. For example, distances of 2.48 and $2.31 \AA$ (reference code YIDFAU) and 2.38, 2.41 and $2.46 \AA$ (reference code YIDFEY) between the oxygen atoms of hydroxyethyl groups and bromide ions were found in multidentate ligands [10]. The structure of an anion binding tripodal host molecule (reference code UMIDEZ), notably a methanol solvate, showed a short contact of $2.53 \AA$ between the oxygen atom of the methanol molecule and a bromide ion [11]. Since a host-guest relationship cannot be seriously considered here, the short $\mathrm{O} \cdots \mathrm{Br}$ distance may rather be due to crystal packing.

Figure 3. (a) ORTEP plot and atom numbering scheme of the cation; (b) packing and hydrogen bonding of 2 .

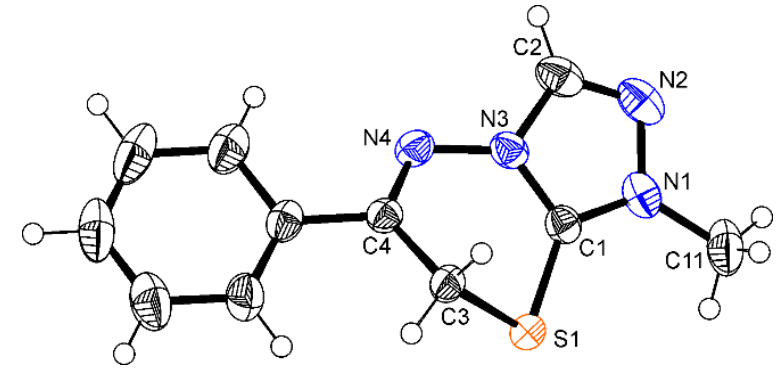

(a)

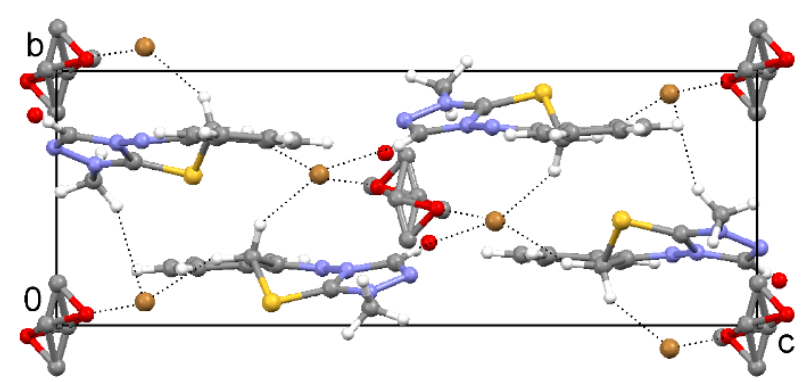

(b)

In contrast, 6-phenyl-1-methyl-1,2,4-triazolo[3,2-b]1,3,4-thiadiazinium bromide (3) precipitated from the hot reaction solution, but did not crystallize as a solvate.The triazole rings are arranged parallel to $\left(\begin{array}{lll}1 & 13 & 7\end{array}\right)$ and $\left(\begin{array}{l}13 \\ 13\end{array}\right)$ planes. The bromide ions receive three hydrogen bonds from $\mathrm{C} 2-\mathrm{H}, \mathrm{C} 3-\mathrm{H}$ and C11-H, linking the cations into cyclic dimers (Figure 4).

Figure 4. (a) ORTEP plot and atom numbering scheme of the cation; (b) packing and hydrogen bonding of $\mathbf{3}$.

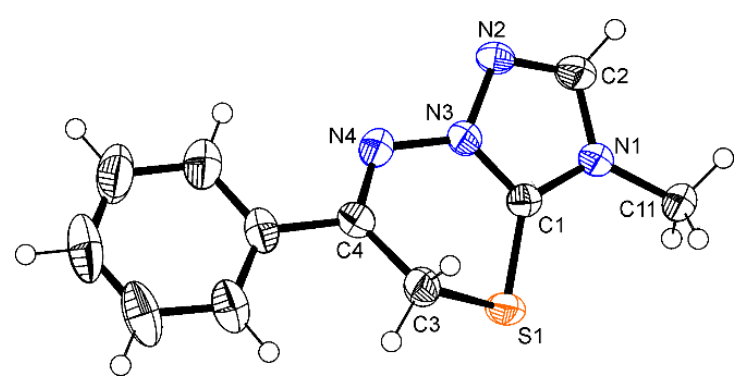

(a)

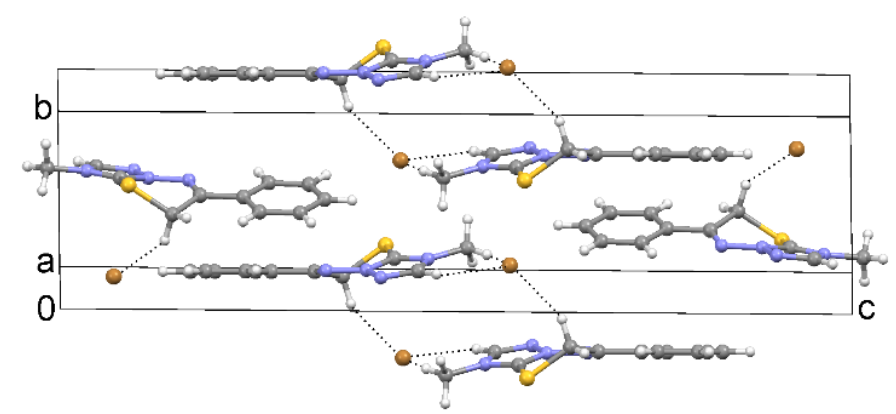

(b)

The thiadiazine rings themselves are quite similar in the three compounds. The $\mathrm{C}-\mathrm{S}-\mathrm{C}$ angles are between $91.5(1)^{\circ}$ and $93.4(2)^{\circ}$. The $\mathrm{S}-\mathrm{C}-\mathrm{C}$ angles range from $111.1(1)^{\circ}$ to $112.6(3)^{\circ}$, and the $\mathrm{N}-\mathrm{C}-\mathrm{C}$ 
angles are between $122.0(2)^{\circ}$ and $123.9(4)^{\circ}$. Figure 5a illustrates the different geometries adopted by the phenylthiadiazinium cations. Differences in the conformation of the phenylthiadiazinium cations are best described by the torsion angles $\psi_{1}$ and $\psi_{2}$. Thus, angles $\psi_{1}$ are $-16.6(3)^{\circ}$ for $1,-9.4(4)^{\circ}$ for 2 , and $-1.0(6)^{\circ}$ for $\mathbf{3}$, whereas $\psi_{2}$ values are $-19.9(3)^{\circ}$ for $\mathbf{1},-12.0(4)^{\circ}$ for $\mathbf{2}$, and $-6.9(6)^{\circ}$ for $\mathbf{3}$, respectively. The differences between the other corresponding torsion angles within the thiadiazine rings are smaller among the three compounds. A graphical summary of these angles is depicted in Figure 5b.

Figure 5. (a) Overlay of the 1,3,4-thiadiazinium cations of $\mathbf{1}$ (green), 2 (blue), and $\mathbf{3}$ (red);

(b) Torsion angles describing the conformation of the thiadiazine rings in the cations 1-3.

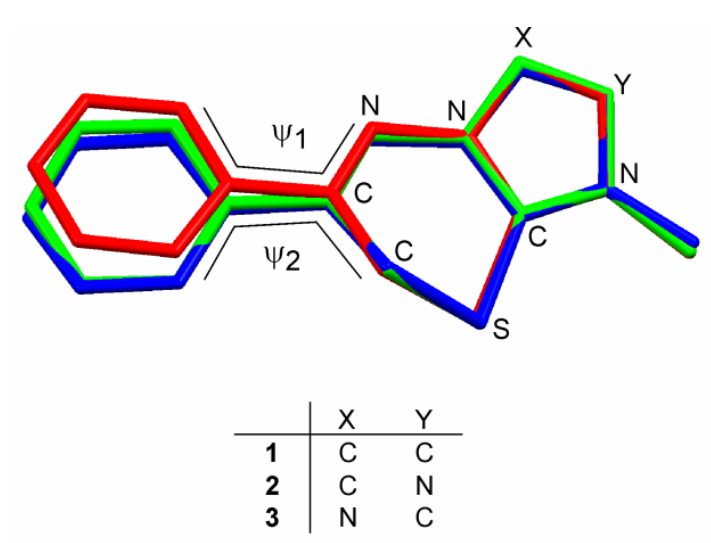

(a)

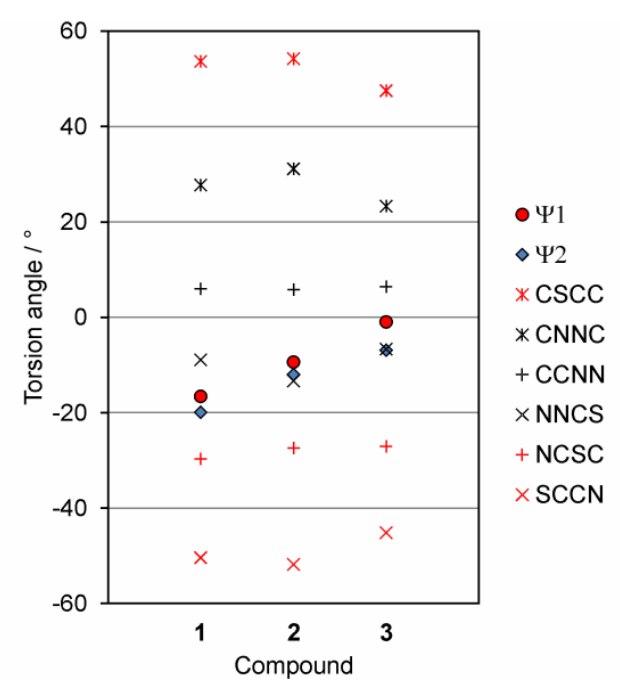

(b)

\section{Experimental Section}

Reagents and solvents were purchased from Sigma-Aldrich (Steinheim, Germany). X-Ray diffraction data were recorded by $\omega$ and $\varphi$ scans with a Nonius KappaCCD (Bruker, Billerica, MA, USA) diffractometer using MoKa radiation at $233 \mathrm{~K}$. The structures were solved by direct methods and refined by full-matrix least-squares methods on $F^{2}$ [12]. CCDC reference numbers: 1014167-1014169. Illustrations were generated using ORTEP-3 [13] and Mercury [14] programs. NMR spectra were measured with Bruker Avance DPX 300 and Bruker Avance II+ 600 spectrometers. IR spectra were obtained with a Bruker Alpha FT-IR instrument.

\subsection{6-Phenyl-1-Methylimidazo[2,1-b]1,3,4-Thiadiazinium Bromide Methanol Solvate (1)}

A solution of 1-amino-3-methylimidazoline-2-thione (50 mg, $0.39 \mathrm{mmol})$ and phenacyl bromide ( $77 \mathrm{mg}, 0.39 \mathrm{mmol})$ in EtOH $(3 \mathrm{~mL})$ was stirred at $80^{\circ} \mathrm{C}$ for $4 \mathrm{~h}$. The solvent was removed under reduced pressure, and the residue was crystallized by slow evaporation of a solution in $\mathrm{MeOH}(1 \mathrm{~mL})$. Yield: $48 \mathrm{mg}$ (40\%). M.p. 219-229 ${ }^{\circ} \mathrm{C}$ (decomposition). ${ }^{1} \mathrm{H}$ NMR (DMSO-d6, $600 \mathrm{MHz}$ ): $\delta 3.82$ (s, 3H), 4.64 (s, 2H), $7.63(\mathrm{t}, J=7.6 \mathrm{~Hz}, 2 \mathrm{H}), 7.69$ (t, $J=7.3 \mathrm{~Hz}, 1 \mathrm{H}), 7.91(\mathrm{~d}, J=2.1 \mathrm{~Hz}, 1 \mathrm{H}), 8.06$ (d, $J=7.4 \mathrm{~Hz}, 2 \mathrm{H}), 8.29$ $(\mathrm{d}, J=2.1 \mathrm{~Hz}, 1 \mathrm{H}) \mathrm{ppm} .{ }^{13} \mathrm{C} \mathrm{NMR}$ (DMSO-d6, $\left.151 \mathrm{MHz}\right): \delta 24.8,36.6,123.0,124.0,129.3(2 \mathrm{C}), 130.6$ (2C), 133.5, 134.2, 138.2, 158.6 ppm. IR (neat): $\widetilde{v} 3078 \mathrm{w}, 2986 \mathrm{w}, 2885 \mathrm{w}, 1591 \mathrm{~m}, 1497 \mathrm{~m}, 1449 \mathrm{~m}$, $1405 \mathrm{~m}, 1319 \mathrm{~m}, 1289 \mathrm{~m}, 837 \mathrm{~m}, 768 \mathrm{~s}, 730 \mathrm{~m}, 688 \mathrm{~s}, 651 \mathrm{~s}, 585 \mathrm{~m} \mathrm{~cm}^{-1}$. 
A solution of 4-amino-1-methyl-1,2,4-triazoline-5-thione (50 $\mathrm{mg}, 0.38 \mathrm{mmol}$ ) and phenacyl bromide $(76 \mathrm{mg}, 0.38 \mathrm{mmol})$ in EtOH $(3 \mathrm{~mL})$ was stirred at $80{ }^{\circ} \mathrm{C}$ for $4 \mathrm{~h}$. On cooling to $20{ }^{\circ} \mathrm{C}$, the product precipitated. It was filtered off and washed with $\mathrm{Et}_{2} \mathrm{O}$. Yield: $60 \mathrm{mg}(50 \%)$. Single crystals were obtained by slow evaporation of a solution in $\mathrm{MeOH}$, m.p. $213-219{ }^{\circ} \mathrm{C}$ (decomposition). ${ }^{1} \mathrm{H}$ NMR (DMSO-d6, $300 \mathrm{MHz}): \delta 1.05$ and $3.43(\mathrm{EtOH}), 4.02(\mathrm{~s}, 3 \mathrm{H}), 4.76(\mathrm{~s}, 2 \mathrm{H}), 7.63-7.73(\mathrm{~m}, 3 \mathrm{H}), 8.07-8.09(\mathrm{~m}, 2 \mathrm{H})$, $9.84(\mathrm{~s}, 1 \mathrm{H}) \mathrm{ppm} .{ }^{13} \mathrm{C}$ NMR (DMSO-d6, $\left.75 \mathrm{MHz}\right): \delta 18.6$ and 56.0 (EtOH), 24.6, 38.0, $128.1(2 \mathrm{C}), 129.4$ (2C), 131.8, 133.4, 142.3, 145.2, 159.4 ppm. IR (neat): $\widetilde{v} 3028 \mathrm{w}, 2961 \mathrm{w}, 2896 \mathrm{w}, 1533 \mathrm{~m}, 1508 \mathrm{~m}$, 1446 m, 1361 m, 1291 m, 1161 m, 1088 m, 839 m, 789 m, 766 s, 681 s, 657 m, 589 m, $512 \mathrm{~m} \mathrm{~cm}^{-1}$.

\subsection{6-Phenyl-1-Methyl-1,2,4-Triazolo[3,2-b]1,3,4-Thiadiazinium Bromide (3)}

A solution of 1-amino-4-methyl-1,2,4-triazoline-5-thione (50 $\mathrm{mg}, 0.38 \mathrm{mmol}$ ) and phenacyl bromide ( $76 \mathrm{mg}, 0.38 \mathrm{mmol})$ in EtOH $(3 \mathrm{~mL})$ was stirred at $80{ }^{\circ} \mathrm{C}$ for $8 \mathrm{~h}$. The product crystallized from the hot solution. It was collected by filtration, washed with $\mathrm{EtOH}$, and dried. Yield: $90 \mathrm{mg}$ (75\%). Single crystals from hot EtOH, m.p. $207-21{ }^{\circ} \mathrm{C}$ (decomposition). ${ }^{1} \mathrm{H}$ NMR (DMSO-d6, $300 \mathrm{MHz}$ ): $\delta 3.87$ (s, 3H), 4.78 (s, 2H), 7.62-7.72 (m, 3H), 8.09-8.12 (m, 2H), 9.34 (s, 1H) ppm. ${ }^{13} \mathrm{C}$ NMR (DMSO-d, $\left.75 \mathrm{MHz}\right): \delta$ 24.1, 33.8, 128.4 (2C), 129.4 (2C), 131.7, 133.4, 143.2, 145.5, 156.8 ppm. IR (neat): $\tilde{v} 3004 \mathrm{w}, 2880 \mathrm{w}$, $1550 \mathrm{~m}, 1474 \mathrm{~m}, 1440 \mathrm{~m}, 1341 \mathrm{~m}, 1327 \mathrm{~m}, 1403 \mathrm{~s}, 1225 \mathrm{~s}, 1073 \mathrm{~m}, 911 \mathrm{~m}, 833 \mathrm{~m}, 767 \mathrm{~s}, 685 \mathrm{~s}, 675 \mathrm{~s}$, $646 \mathrm{~m}, 635 \mathrm{~s}, 507 \mathrm{~m} \mathrm{~cm}^{-1}$.

\section{Conclusions}

The annelated heterocycles are derived from bifunctional aminothiones. These are the first crystal structures of azolo[b]1,3,4-thiadiazinium salts. We intend to continue research in this field.

\section{Author Contributions}

Gerhard Laus conceived and designed this study, carried out experimental work (synthesis, crystallization and characterization) and wrote the manuscript. Klaus Wurst determined the crystal structures. Herwig Schottenberger facilitated and supported this study.

\section{Conflicts of Interest}

The authors declare no conflict of interest.

\section{References}

1. Becker, H.G.O.; Nagel, D.; Timpe, H.-J. Preparation and reactions of 1-alkyl-4-amino5-(alkylthio)-s-triazolium salts. J. Prakt. Chem. 1973, 315, 1131-1138. (In German)

2. Laus, G.; Klötzer, W. 1-Amino-1H-1,2,4-triazole derivatives. Synthesis 1990, 22, 707-712.

3. Kuzmenko, V.V.; Kuzmenko, T.A.; Pozharskii, A.F.; Kryshtalyuk, O.V. 1-Amino-3-alkylbenzimidazoline-2-thiones(selenones). Khim. Geterotsikl. Soedin. 1990, 1689-1690. (In Russian) 
4. $\quad$ Laus, G.; Kahlenberg, V.; Wurst, K.; Müller, T.; Kopacka, H.; Schottenberger, H. Synthesis and crystal structures of new 1,3-disubstituted imidazoline-2-thiones. Z. Naturforsch. b 2013, 68, 1239-1252.

5. Laus, G.; Kahlenberg, V.; Wurst, K.; Schottenberger, H. Synthesis and crystal structures of new 1,4-disubstituted 1,2,4-triazoline-5-thiones. Z. Naturforsch. b 2014, 69, 950-964.

6. Alajarin, M.; Molina, P.; de Vega, M.J.P.; Foces-Foces, M.; Cano, F.H.; Claramunt, R.M.; Elguero, J. Aromatic systems with $10 \pi$ electrons derived from 3a-azapentalene. Part 42. Research in the pyrazolo[5,1-c]-1,2,4-triazole series. Chem. Scr. 1985, 25, 230-238.

7. Kuzmenko, T.A.; Kuzmenko, V.V.; Kryshtalyuk, O.V.; Pozharsky, A.F. Ring contraction of thia(seleno)diazine to pyrazole ring by reaction of 3-aryl-10-methyl-2H-1,3,4-thia(seleno)diazino[3,2-a]benzimidazolium salts with bases. Khim. Geterotsikl. Soedin. 1992, 1698-1705. (In Russian)

8. Kröger, C.-F.; Tenor, E.; Beyer, H. 1,2,4-Triazoles. II Reaction of methyl-substituted thiocarbohydrazides with aliphatic carboxylic acids. Liebigs Ann. Chem. 1961, 643, 121-128. (In German)

9. Becker, H.G.O; Nagel, D.; Timpe, H.-J. C-H-Acid reactions of 1-alkyl-4-amino-1,2,4-triazolium salts. J. Prakt. Chem. 1973, 315, 97-105. (In German)

10. Crisostomo-Lucas, C.; Toscano, R.A.; Morales-Morales, D. Synthesis and characterization of new potentially hydrosoluble pincer ligands and their application in Suzuki-Miyaura cross-coupling reactions in water. Tetrahedron Lett. 2013, 54, 3116-3119.

11. Wallace, K.J.; Belcher, W.J.; Turner, D.R.; Syed, K.F.; Steed, J.W. Slow anion exchange, conformational equilibria, and fluorescent sensing in Venus Flytrap aminopyridinium-based anion hosts. J. Am. Chem. Soc. 2003, 125, 9699-9715.

12. Sheldrick, G.M. A short history of SHELX. Acta Crystallogr. 2008, A64, 112-122.

13. Farrugia, L.J. ORTEP-3 for Windows-A version of ORTEP-III with a Graphical User Interface (GUI). J. Appl. Cryst. 1997, 30, doi:10.1107/S0021889897003117.

14. Macrae, C.F.; Edgington, P.R.; McCabe, P.; Pidcock, E.; Shields, G.P.; Taylor, R.; Towler, M.; van de Streek, J. Mercury: Visualization and analysis of crystal structures. J. Appl. Cryst. 2006, $39,453-457$.

(C) 2014 by the authors; licensee MDPI, Basel, Switzerland. This article is an open access article distributed under the terms and conditions of the Creative Commons Attribution license (http://creativecommons.org/licenses/by/4.0/). 